\title{
Adequacy of Cancer-Related Pain Treatments and Factors Affecting Proper Management in Ayder Comprehensive Specialized Hospital, Mekelle, Ethiopia
}

\author{
Kald Beshir Tuem, ${ }^{1}$ Leake Gebremeskel ${ }^{D},{ }^{2}$ Kibrom Hiluf, ${ }^{3}$ Kbrom Arko, ${ }^{1}$ \\ and Haftom Gebregergs Hailu ${ }^{1}$ \\ ${ }^{1}$ Department of Pharmacology and Toxicology, School of Pharmacy, College of Health Sciences, Mekelle University, \\ Mekelle, Ethiopia \\ ${ }^{2}$ Department of Pharmacy, College of Health Sciences, Aksum University, Aksum, Ethiopia \\ ${ }^{3}$ Department of Oncology, School of Medicine, College of Health Sciences, Mekelle University, Mekelle, Ethiopia
}

Correspondence should be addressed to Leake Gebremeskel; lemeskel2005@gmail.com

Received 27 January 2020; Revised 23 July 2020; Accepted 11 September 2020; Published 24 September 2020

Academic Editor: Ozkan Kanat

Copyright (c) 2020 Kald Beshir Tuem et al. This is an open access article distributed under the Creative Commons Attribution License, which permits unrestricted use, distribution, and reproduction in any medium, provided the original work is properly cited.

\begin{abstract}
Background. Cancer-related pain (CRP) is a major problem with a potential negative impact on quality of life of the patients and their caregivers. Purpose. To assess the adequacy of cancer-related pain management in Ayder Comprehensive Specialized Hospital (ACSH). Methodology. A facility-based cross-sectional study design was conducted in ACSH from January to March 2019. A well-structured professional-assisted questionnaire using Brief Pain Inventory-Short Form (BPI-SF) was used to collect data concerning the severity of pain, functioning interference, and adequacy of pain management in cancer patients. Data were analyzed using SPSS v.21. Result. Out of 91 participants, 47 (51.6\%) were male and $52(57.1 \%)$ were between the age group of $18-45$, with the mean age of $44.8 \pm 13.6$ years. According to the pain assessment tool (BPI), 85 (93.4\%) patients experienced pain and $90(98.9 \%)$ patients had activity interference; negative pain management index (PMI) was observed in 40 (43.95\%) patients, showing that $43.95 \%$ were receiving inadequate pain management. Out of 38 patients who received no analgesics, $35.2 \%$ were found to have inadequate pain management, whereas those who took strong opioids had $100 \%$ effective pain management and the majority of the patients were in stage III. Among 38 (41.76\%) only $20(52.63 \%)$ received adequate pain management, based on patients' self-report in which $18.7 \%$ of the participants stated that they got $30 \%$ pain relief and only $1.1 \%$ got $90 \%$ relief. The predictors of undertreatment were presence of severe pain, metastasis, comorbidity, and stage of the cancer and could also be due to the educational level and monthly income, as evidenced by significant association. Conclusion. This study suggests that cancer pain management in ACSH was sufficient for only 56\%. However, large numbers of individuals are suffering from a manageable pain. Hence, remedial action should be taken, including increasing awareness of symptom management in medical staff and incorporating existing knowledge into routine clinical practice.
\end{abstract}

\section{Introduction}

Cancer is a disease condition in which the body's cells begin to grow and proliferate in an uncontrollable way $[1,2]$. The major cause of cancer, $90-95 \%$ of cases, is due to genetic mutations from environmental factors and the remaining $5-10 \%$ is by inherited genetics [3]. The pathophysiology of cancer is very complex in which malignancy occurs through overexpression of normal oncogenes or underexpression of tumor suppressor genes. The report from the World Health Organization (WHO) [4] shows that cancer is the major cause of morbidity and mortality globally, 18.1 million new cases and 9.6 million deaths annually. Popat et al. [5] highlighted that cancer and other noncommunicable diseases are estimated to surpass some infectious diseases as leading causes of death in the African region by the year 
2030. In Ethiopia, it accounts for $4 \%$ of all deaths and approximately 60,000-125,000 cancer patients visit the Tikur Anbessa Specialized Hospital (TASH) oncology unit annually [2].

According to previous studies, greater than half of the patients with cancer experience pain from moderate to severe intensity $[6,7]$. Cancer-related pain (CRP) can be nociceptive pain which comes from the actual damage of nonneural tissues and neuropathic pain which is caused by damage of the somatosensory nervous system $[3,6,8]$. Pain assessment is an integral component of cancer pain management which aims at identifying pain characteristics, pain etiology, specific pain syndromes, and analgesic targets using pain management index (PMI) [9]. To manage CRP effectively, the WHO has developed a 3-step pain ladder which includes the use of a nonopioid (paracetamol) for mild pain, a weak opioid (Codeine) for moderate pain, and a strong opioid (morphine) for severe pain [10].

Despite the availability of many guidelines for the treatment of CRP, patients usually receive inadequate pain management as highlighted by studies from different parts of the world. A report in Japan shows physicians undertreated CRP in $70 \%$ of patients [11]. In a crosssectional study in Portugal, patients' pain management index status suggests that cancer-related pain treatment was insufficient in $25.6 \%$ of patients and about 1 in 4 patients was poorly treated at first consultation in the CRP clinic [12]. Moreover, a meta-analysis showed that pooled prevalence rates of cancer-related pain in patients treated with disease-modifying treatment and in advanced terminal disease were found to be $55 \%$ and $64 \%$, respectively $[13,14]$. As studies indicate, the burden of cancer-related pain in developing countries is too high where approximately $80 \%$ of individuals die from cancerrelated moderate or severe pain lasting for 90 days $[4,15]$. Although adequacy of CRP management study is too limited in Ethiopia, one study conducted in Gondar showed that $65 \%$ of patients did not get adequate CRP management [16]. As the adequacy of CRP treatment is not well studied in Ayder Comprehensive Specialized Hospital (ACSH) so far, we aimed to evaluate the adequacy of CRP management and its determinants. Hence, this research could be utilized as a starting point for further research and improvement of CRP management in the hospital oncology center.

\section{Methods}

2.1. Study Area. This research was done at Mekelle University, Ayder Comprehensive and Specialized Hospital, located in Tigray, Northern Ethiopia. The hospital was established to provide educational and medical services in 2008 to around 9 million people from Tigray and neighboring regions such as Afar and Northeastern Amhara and Eritrea. It renders a variety of medical services for all age groups in both inpatient and outpatient departments. Ayder Comprehensive and Specialized Hospital is the second largest hospital in the country. It has about 500 inpatient beds in all departments including the oncology unit [17].
2.2. Study Design and Period. A cross-sectional study design was conducted from January 01 to March 30, 2019, to assess CRP in the oncology unit of ACSH.

2.3. Study Population. Study population included all adult cancer patients visiting Ayder Comprehensive Specialized Hospital during the study period.

2.4. Inclusion Criteria. Cancer patients who meet the following criteria were included in the study: eighteen years old and greater; patients diagnosed with any kind of cancer; and all patients in the outpatient and inpatient wards of the oncology unit at specified time duration.

2.5. Exclusion Criteria. Terminally ill patients, patients with neurologic disorders, and individuals who refuse to participate in the study were excluded.

2.6. Sample Size Determination. All patients who attended the outpatient and inpatient oncology department at the specified study period were included in the study in a census manner as long as they meet the inclusion criteria.

2.7. Data Collection Procedure. Data were collected using the Brief Pain Inventory-Short Form (BPI-SF) [18] and chart review. The questionnaire-based data collection has an 8item questionnaire which was applied to assess the impact and severity of pain on the daily functioning of the patient. The eight items of the questionnaire, BPI-SF, are described as follows: item number 1 is used to indicate a specific part of the body or coverage of pain where patients feel; items numbers 2 to 5 assess the severity of pain. The calculation of pain severity score was performed by dividing the total score from item numbers 2 to 5 by 4 [19], which gives severity out of ten. The type of medication given and the percentage of pain relief of patients were described by item numbers 6 and 7. Pain interference in seven daily activities was measured using item number 8 (8.1 up to 8.7 ), and pain interference was calculated by dividing the sum of the scores for each query (from 8.1 up to 8.7 ) by 7 . This also produces an interference score out of ten in which items of interference were put with $0-10$ scales denoting that 0 shows no interference, whereas 10 indicates full interference. Finally, using BPI-SF, severity and interference pain was classified into 4 groups: no pain (0), mild (1 up to 3 ), moderate (4 up to 7 ), and severe ( 8 up to 10 ).

Much information was collected from the patient including sociodemographic variables, comorbidity status, patient diagnoses, cancer location and stages, presence or absence of metastases, treatment modality, and number of drugs given and analgesics prescribed. The questionnaire was first translated into Tigrigna (the locally official language) and then translated back to English to verify accuracy. Clinical data were gathered from chart review, and type and severity of pain grading, analgesic use with percentage of 
pain interference, and relief of pain were collected by interviewing patients using the BPI-SF data collection tool.

According to the type of antipain medication(s) patient uses, scores were given as follows: 0 (no analgesic drug), 1 (nonopioid antipain drug), 2 (weak opioid), and 3 (strong opioid), and then PMI was determined. Four levels of analgesic medications were estimated by the potency: $(0)$ no order for antipain drug, (1) nonopioid (nonsteroidal anti-inflammatory drugs), (2) weak opioid (codeine), and (3) strong opioid (morphine), and then potency of drugs was compared with " worst pain." No pain was scored as " 0 ," mild pain " 1 ," moderate pain "2," and severe pain "3." Finally, the PMI is determined by subtracting the pain level from the analgesic level in which the values go from -3 (severe pain with no analgesic medication) to +3 (morphine use and no pain reported). Therefore, inadequate pain management is considered when negative PMI is scored.

\section{Variables}

\subsection{Dependent Variable}

Cancer-related pain management

Pain-related interferences

\subsection{Independent Variables}

Age, sex, religion, ethnicity, educational status, family size, residence, income, marital status, stage of cancer, type of cancer, and site of cancer-related pain.

Antipain medication administration

3.3. Data Management and Analysis. Statistical analysis was done using SPSS version 21. Descriptive statistics was used to summarize demographic characteristics, pain type, and number and type of analgesics given to the patient. Adequacy of cancer pain management and pain interference were cross tabulated to compare the magnitude among different variables. Association was tested between independent and dependent variables using the chi-square test. Significance level was set by fixing $p<0.05$.

3.4. Data Quality Control. The questionnaire was pretested in a total of 20 individuals at a hospital which is not a study site (Mekelle hospital). The completeness of the questionnaire was checked step by step by the data collectors and supervisors and further counterchecked by the principal investigator daily.

\section{Result}

A total of ninety-one (91) participants were included in the study. Nearly half of the patients $(47(51.6 \%))$ were male while the rest were females $(48.4 \%)$. Majority of them (74 $(81.3 \%)$ ) were Orthodox Christians. The mean age was $44.8 \pm 13.6$ years ranging from 19 to 72 years, sixty-three $(69.2 \%)$ were from urban areas. The mean income of a family was $3590.2 \pm 2336.5$, and the family size of the participants was $4.97 \pm 3.06$ (Table 1 ).
Of the total number of participants, 81 (89\%) were admitted. Only $6(6.6 \%)$ patients had comorbidities. As the study indicates, 22 (22\%), 38 (41.8\%), and $33(36.3 \%)$ patients were in stages II, III, and IV, respectively. It was observed that $42(46.1 \%)$ of the patients were with metastasized cancer. Nearly fifty percent of the patients (50 (54.9\%)) experienced a moderate severity of pain. Most of the patients $(59(64.8 \%))$ received chemotherapy plus surgical intervention (Table 2).

With regard to the type of pain, most patients experienced a mixed type of pain $(44(48.4 \%))$ followed by nociceptive pain (16 (17.6\%)) (Table3).

The commonest site of CRP was in the intestinal area 31 (34.1\%), followed by genitourinary $(18(19.8 \%))$, and least at the amputated site $(1(1.1 \%))$ (Table 4$)$.

According to the information collected using the pain assessment tool (BPI), 85 (93.4\%) patients experienced pain, of which $50(54.9 \%)$ had moderate pain, while only $6(6.6 \%)$ felt no pain. Likewise, almost all (90 (98.9\%)) patients had pain functioning interference; among those, 36 (39.6\%) patients faced moderate pain and $32(35.2 \%)$ felt severe pain (Table 5).

While investigating the adequacy of pain treatment, negative PMI was observed in 40 (43.95\%) patients showing that they were receiving inadequate pain management. Most of the patients $(51(56.04 \%))$ had received adequate management of pain (Figure 1).

Out of the 38 patients who received no analgesics, 32 (84\%) had inadequate pain management while $100 \%$ effective pain management in patients taking strong opioids (Figure 2).

Upon crosstab and Pearson chi-square analysis of the adequacy of CRP treatment and pain functioning interference, it was revealed that pain was more significantly adequately managed in patients with the following characteristics: age ranging from 18 to 45 years, males, orthodox, married, illiterate, urban dwellers, having $>5000$ monthly income, stage III and stage IV of the disease, absence of metastasis, being treated with chemotherapy plus surgery, absence of comorbidity, having moderate pain severity, and being on strong opioids + nonopioids + adjuvant. With regard to pain interference presence on functioning, moderate to severe interference of pain was most likely to be present in patients with the following characteristics: age ranging from 18 to 45 years, males, orthodox, divorced, illiterate, urban dwellers, having $\leq 2000$ monthly income, stage III of the disease, presence of metastasis, being treated by combination therapy, absence of comorbidity, presence of history of pain, moderate pain severity, and being on strong opioids + nonopioids + adjuvant (Tables 6-8).

Forty-four $(48.35 \%)$ patients had mixed type of pain, of which 28 (63.6\%) were adequately treated and $42(95.5 \%)$ had moderate to severe functioning interference. Regarding the staging of cancer, the majority of patients were on stage III 38 (41.76\%), of which $20(52.63 \%)$ received adequate pain management and $28(73.7 \%)$ faced moderate to severe functioning interference (Figure 3).

The patients were allowed to self-report their relief to the provided analgesics and only $18.7 \%$ of the patients have responded that the drugs prescribed reduced their pains by 
TABle 1: Demographic details of cancer patients at the oncology unit of ACSH, Mekelle, Ethiopia $(n=91)$.

\begin{tabular}{|c|c|c|}
\hline Variables & Frequency & Percentage \\
\hline \multicolumn{3}{|l|}{ Gender } \\
\hline Male & 47 & 51.6 \\
\hline Female & 44 & 48.4 \\
\hline \multicolumn{3}{|c|}{ Age category in years* } \\
\hline $18-45$ & 52 & 57.1 \\
\hline $46-65$ & 33 & 36.3 \\
\hline$\geq 65$ & 6 & 6.6 \\
\hline \multicolumn{3}{|l|}{ Residence } \\
\hline Rural & 28 & 30.8 \\
\hline Urban & 63 & 69.2 \\
\hline \multicolumn{3}{|l|}{ Region } \\
\hline Tigray & 89 & 97.8 \\
\hline Afar & 1 & 1.1 \\
\hline Others & 1 & 1.1 \\
\hline \multicolumn{3}{|l|}{ Religion } \\
\hline Orthodox & 74 & 81.3 \\
\hline Protestant & 9 & 9.9 \\
\hline Muslim & 8 & 8.8 \\
\hline \multicolumn{3}{|l|}{ Occupation } \\
\hline Student & 11 & 12.1 \\
\hline Governmental & 12 & 13.2 \\
\hline Merchant & 15 & 16.5 \\
\hline Farmer & 33 & 36.3 \\
\hline Private & 9 & 9.9 \\
\hline None & 11 & 12.1 \\
\hline \multicolumn{3}{|l|}{ Marital status } \\
\hline Married & 65 & 71.4 \\
\hline Single & 14 & 15.4 \\
\hline Widowed & 6 & 6.6 \\
\hline Divorced & 6 & 6.6 \\
\hline \multicolumn{3}{|l|}{ Income range** } \\
\hline$\leq 2000$ & 18 & 19.8 \\
\hline $2001-5000$ & 10 & 11 \\
\hline$>5000$ & 14 & 15.4 \\
\hline Missing (no data) & 49 & \\
\hline \multicolumn{3}{|l|}{ Family size*** } \\
\hline $1-3$ & 13 & 14.3 \\
\hline $4-6$ & 33 & 36.3 \\
\hline$>6$ & 31 & 34.1 \\
\hline 0 & 14 & 15.4 \\
\hline
\end{tabular}

Mean $=* 44.8 \pm 13.6 ; * * 3590.2 \pm 2336.5 ; * * * 4.97 \pm 3.06$.

$30 \%$. Relatively small percentage $(1.1 \%)$ of the patients got $90 \%$ relief while $11 \%$ of the participants exercised $0 \%$ effective pain relief (Figure 4).

\section{Discussion}

Pain is one of the most frequent and distressing symptoms experienced by cancer patients, and it affects their quality of life [11]. However, evidence from clinical practice indicates that pain of cancer patients may be treated in up to $90 \%$ cases with the current analgesics [20-22]. Limited researches have been done on the adequacy of CRP in Ethiopia, and to the best of our knowledge, there is no study conducted in ACSH. It is believed that this study will be used as a baseline for further research regionally and nationally.
TABLE 2: Health-related variables of cancer patients at the oncology unit of ACSH, Mekelle, Ethiopia $(n=91)$.

\begin{tabular}{lcc}
\hline Variables & Frequency & Percentage \\
\hline Stage & 20 & \\
II & 38 & 22 \\
III & 33 & 41.8 \\
IV & & 36.3 \\
\hline Type of patient & 81 & \\
Admitted & 10 & 89 \\
Ambulatory & & 11 \\
\hline Metastasis & 42 & \\
Present & 49 & 56.1 \\
Absent & & \\
\hline Pain severity & 6 & 29.7 \\
No pain & 27 & 54.9 \\
Mild & 50 & 8.8 \\
Moderate & 8 & 35.2 \\
Severe & & 64.8 \\
\hline Treatment modality & 32 & \\
Chemo therapy only & 59 & \\
Chemo therapy + surgery &
\end{tabular}

TABLE 3: Type of pain experienced by cancer patients at the oncology unit of ACSH, Mekelle, Ethiopia $(n=91)$.

\begin{tabular}{lcc}
\hline Type of pain & Frequency & Percentage \\
\hline Nociceptive & 16 & 17.6 \\
Neuropathic & 13 & 14.3 \\
Mixed & 44 & 48.4 \\
Missing (no data) & 12 & 13.2 \\
\hline
\end{tabular}

TABle 4: Common site of cancer-related pain among cancer patients at the oncology unit of ACSH, Mekelle, Ethiopia $(n=91)$.

\begin{tabular}{lcc}
\hline Site of pain & Frequency & Percentage \\
\hline Lung & 14 & 15.4 \\
Genitourinary & 18 & 19.8 \\
Head and neck & 12 & 13.2 \\
Intestine & 31 & 34.1 \\
Amputated site & 1 & 1.1 \\
Breast & 4 & 4.4 \\
Nonspecified & 11 & 12.1 \\
\hline
\end{tabular}

In this study, a total of 91 cancer patients participated. It was found that $93.4 \%$ of them had cancer-related pain. This is comparable with the study result from Gondar, Ethiopia, which reported $91.6 \%$ of cancer patients experience CRP [16], but much higher as compared to the study result from Portugal, which claimed only 25\% of patients had CRP [12]. Previous studies have indicated that this difference could be due to low awareness of clinicians on assessment of CRP, lack of updated guidelines, and shortage of analgesics such as morphine [23, 24].

According to this study, $43.9 \%$ of patients received inadequate pain management, which is lower in comparison to a study result from Gondar which reported $65 \%$ of cancer 
TABLE 5: Pain severity and pain interference among cancer patients at the oncology unit of ACSH, Mekelle, Ethiopia ( $n=91)$.

\begin{tabular}{|c|c|c|c|}
\hline \multicolumn{2}{|c|}{ Pain related variables } & Frequency & Percentage \\
\hline \multirow{4}{*}{ Severity of pain } & No pain & 6 & 6.6 \\
\hline & Mild & 27 & 29.7 \\
\hline & Moderate & 50 & 54.9 \\
\hline & Severe & 8 & 8.8 \\
\hline \multirow{4}{*}{ Pain interference severity } & No interference & 1 & 1.1 \\
\hline & Mild & 22 & 24.2 \\
\hline & Moderate & 36 & 39.6 \\
\hline & Severe & 32 & 35.2 \\
\hline \multirow{6}{*}{ Pain management index } & 2 & 6 & 6.6 \\
\hline & 1 & 10 & 11.0 \\
\hline & 0 & 35 & 38.5 \\
\hline & -1 & 21 & 23.1 \\
\hline & -2 & 18 & 19.8 \\
\hline & -3 & 1 & 1.1 \\
\hline \multirow{2}{*}{ Adequacy of pain management } & Adequate & 51 & 56.04 \\
\hline & Inadequate & 40 & 43.95 \\
\hline
\end{tabular}

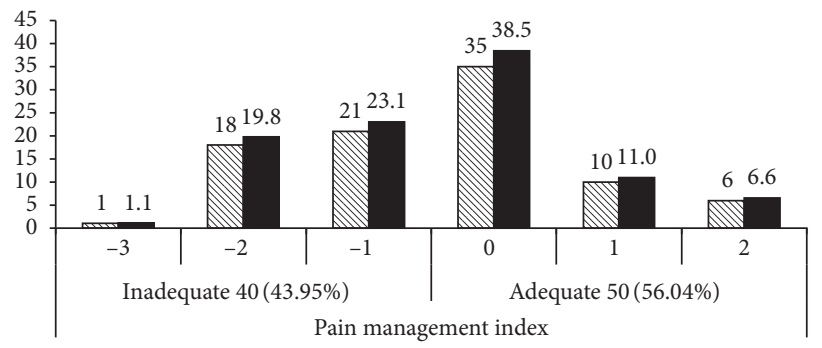

\& Frequency

- Percentage

FIgURE 1: PMI and the number of patients with adequate or inadequate management of pain at the oncology unit of ACSH, Mekelle, Ethiopia.

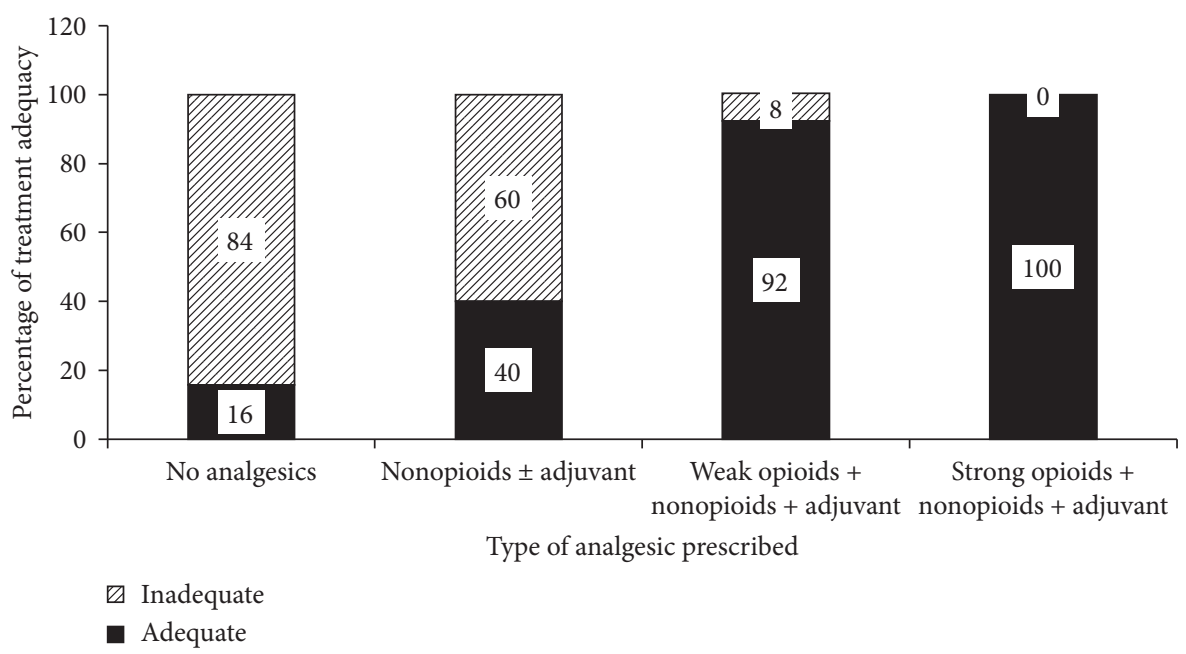

FIgURE 2: Percentage of CRP treatment adequacy within types of analgesics prescribed at the oncology unit of ACSH, Mekelle, Ethiopia.

patients had received inadequate pain management [16]. However, it was found that our result was higher as compared to a research performed in Portugal (25.6\%) [12] and in Ghana (26.4\%) [25]. The main determinants in CRP treatment are patient-related factors [26, 27], disease conditions including stage of cancer (all patients were with stage II and above) and presence of metastasis (42\%), and healthcare provider-related factors [28] that may contribute to the undertreatment of cancer-related pain, which were not assessed in this study. 
TABLE 6: Relationship among sociodemographic variables and adequacy of management and pain interference at the oncology unit of ACSH, Mekelle, Ethiopia $(n=91)$.

\begin{tabular}{|c|c|c|c|c|c|c|c|}
\hline & \multicolumn{2}{|c|}{ Adequacy of treatment, $n(\%)$} & \multirow{2}{*}{$\begin{array}{l}\text { Association } \\
X^{2}, p \text { value }\end{array}$} & \multicolumn{3}{|c|}{ Pain functioning interference, $n(\%)$} & \multirow[t]{2}{*}{ Association } \\
\hline & Adequate & Inadequate & & No/mild & Moderate/severe & $X^{2}, p$ value & \\
\hline \multirow{4}{*}{ Age range } & & & & $5.21,0.074$ & & & $1.44,0.488$ \\
\hline & $18-45$ & $33(36.3)$ & $19(20.9)$ & & $15(16.5)$ & $37(40.7)$ & \\
\hline & $46-65$ & $17(18.7)$ & $16(17.6)$ & & $6(6.6)$ & $27(29.7)$ & \\
\hline & $>65$ & $1(1.1)$ & $5(5.5)$ & & $2(2.2)$ & $4(4.4)$ & \\
\hline \multirow{3}{*}{ Sex } & & & & $2.39,0.122$ & & & $0.00,0.953$ \\
\hline & Male & $30(33.0)$ & $17(18.7)$ & & $12(13.2)$ & $35(38.5)$ & \\
\hline & Female & $21(23.1)$ & $23(25.3)$ & & $11(12.1)$ & $33(36.3)$ & \\
\hline \multirow{4}{*}{ Religion } & & & & $2.20,0.333$ & & & $1.08,0.584$ \\
\hline & Orthodox & $39(42.9)$ & $35(38.5)$ & & $20(22.0)$ & $54(59.3)$ & \\
\hline & Protestant & $7(7.7)$ & $2(2.2)$ & & $1(1.1)$ & $8(8.8)$ & \\
\hline & Muslim & $5(5.5)$ & $3(3.3)$ & & $2(2.2)$ & $6(6.6)$ & \\
\hline \multirow{5}{*}{ Family size } & & & & $3.83,0.281$ & & & $1.18,0.758$ \\
\hline & 0 & $8(8.8)$ & $6(6.6)$ & & $2(2.2)$ & $12(13.2)$ & \\
\hline & $1-3$ & $10(11.0)$ & $3(3.3)$ & & $4(4.4)$ & $9(9.9)$ & \\
\hline & $4-6$ & $19(20.9)$ & $14(15.4)$ & & $9(9.9)$ & $24(26.4)$ & \\
\hline & $>6$ & $14(15.4)$ & $17(18.7)$ & & $8(8.8)$ & $23(25.3)$ & \\
\hline \multirow{7}{*}{ Occupation } & & & & $4.86,0.433$ & & & $4.02,0.547$ \\
\hline & Student & $8(8.8)$ & $3(3.3)$ & & $1(1.1)$ & $10(11.0)$ & \\
\hline & Government employee & $7(7.7)$ & $5(5.5)$ & & $4(4.4)$ & $8(8.8)$ & \\
\hline & Merchant & $10(11.0)$ & $5(5.5)$ & & $6(6.6)$ & $9(9.9)$ & \\
\hline & Farmer & $16(17.6)$ & $17(18.7)$ & & $8(8.8)$ & $25(27.5)$ & \\
\hline & Private work & $6(6.6)$ & $3(3.3)$ & & $2(2.2)$ & $7(7.7)$ & \\
\hline & Not working & $4(4.4)$ & $7(7.7)$ & & $2(2.2)$ & $9(9.9)$ & \\
\hline \multirow{5}{*}{ Marital status } & & & & $8.50,0.037 *$ & & & $6.40,0.094$ \\
\hline & Married & $36(39.6)$ & $29(31.9)$ & & $1(1.1)$ & $(101.0)$ & \\
\hline & Single & $8(8.8)$ & $6(6.6)$ & & $4(4.4)$ & $8(8.8)$ & \\
\hline & Widowed & $1(1.1)$ & $5(5.5)$ & & $6(6.6)$ & $9(9.9)$ & \\
\hline & Divorced & $6(6.6)$ & $0(0)$ & & $8(8.8)$ & $25(27.5)$ & \\
\hline \multirow{5}{*}{ Education level } & & & & $10.66,0.014 *$ & & & $0.50,0.919$ \\
\hline & Illiterate & $18(19.8)$ & $25(27.5)$ & & $12(13.2)$ & $31(34.1)$ & \\
\hline & Primary & $13(14.3)$ & $2(2.2)$ & & $3(3.3)$ & $12(13.2)$ & \\
\hline & Secondary school & $10(11.0)$ & $4(4.4)$ & & $3(3.3)$ & $11(12.1)$ & \\
\hline & College or university & $10(11.0)$ & $9(9.9)$ & & $5(5.5)$ & $14(15.4)$ & \\
\hline \multirow{3}{*}{ Residence } & & & & $0.10,0.751$ & & & $0.32,0.574$ \\
\hline & Rural & $15(16.5)$ & $13(14.3)$ & & $6(6.6)$ & $22(24.2)$ & \\
\hline & Urban & $36(39.6)$ & $27(29.7)$ & & $17(18.7)$ & $46(50.5)$ & \\
\hline \multirow{3}{*}{ Income range } & & & & $1.75,0.417$ & & & $0.22,0.895$ \\
\hline & $\leq 2000$ & $9(9.9)$ & $9(9.9)$ & & $7(7.7)$ & $11(12.1)$ & \\
\hline & $2001-5000$ & $5(5.5)$ & $5(5.5)$ & & $3(3.3)$ & $7(7.7)$ & \\
\hline
\end{tabular}

TABLE 7: Relationship among clinical variables and adequacy of management and pain interference at the oncology unit of ACSH, Mekelle, Ethiopia $(n=91)$.

\begin{tabular}{|c|c|c|c|c|c|c|c|}
\hline & \multicolumn{2}{|c|}{ Adequacy of treatment, $n(\%)$} & \multirow{2}{*}{$\begin{array}{l}\text { Association } \\
\mathrm{X}^{2}, p \text { value }\end{array}$} & \multicolumn{3}{|c|}{ Pain functioning interference, $n(\%)$} & \multirow[t]{2}{*}{ Association } \\
\hline & Adequate & Inadequate & & No/mild & $\begin{array}{c}\text { Moderate/ } \\
\text { severe }\end{array}$ & $\begin{array}{l}\mathrm{X}^{2}, p \\
\text { value }\end{array}$ & \\
\hline \multirow{3}{*}{ Type of patient status } & & & & $0.167,0.683$ & & & $\begin{array}{r}7.173 \\
0.007 * *\end{array}$ \\
\hline & Admitted & $46(50.5)$ & $35(38.5)$ & & $17(18.7)$ & $64(70.3)$ & \\
\hline & Ambulatory & $5(5.5)$ & $5(5.5)$ & & $6(6.6)$ & $4(4.4)$ & \\
\hline \multirow{8}{*}{ Site of cancer } & & & & $\begin{array}{c}11.581 \\
0.072\end{array}$ & & & $12.092,0.600$ \\
\hline & Genitourinary cancer & $5(5.5)$ & $12(13.2)$ & & $7(7.7)$ & $10(11.0)$ & \\
\hline & Gastrointestinal cancer & $11(12.1)$ & $13(14.3)$ & & $10(11.0)$ & $14(15.4)$ & \\
\hline & Breast cancer & $3(3.3)$ & $1(1.1)$ & & $0(0)$ & $4(4.4)$ & \\
\hline & Head and neck cancer & $9(9.9)$ & $3(3.3)$ & & $1(1.1)$ & $11(12.1)$ & \\
\hline & $\begin{array}{c}\text { Bronchopulmonary } \\
\text { cancer }\end{array}$ & $8(8.8)$ & $5(5.5)$. & & $1(1.1)$ & $12(13.2)$ & \\
\hline & Follicular lymphoma & $3(3.3)$ & $0(0)$ & & $0(0)$ & $3(3.3)$ & \\
\hline & Others & $12(13.2)$ & $6(6.6)$ & & $4(4.4)$ & $14(15.4)$ & \\
\hline
\end{tabular}


TABLE 7: Continued.

\begin{tabular}{|c|c|c|c|c|c|c|c|}
\hline & \multicolumn{2}{|c|}{ Adequacy of treatment, $n(\%)$} & \multirow{2}{*}{$\begin{array}{l}\text { Association } \\
\mathrm{X}^{2}, p \text { value }\end{array}$} & \multicolumn{3}{|c|}{ Pain functioning interference, $n(\%)$} & \multirow[t]{2}{*}{ Association } \\
\hline & Adequate & Inadequate & & No/mild & $\begin{array}{c}\text { Moderate/ } \\
\text { severe }\end{array}$ & $\begin{array}{l}\mathrm{X}^{2}, p \\
\text { value }\end{array}$ & \\
\hline \multirow{4}{*}{ Stage of tumor } & & & & $0.467,0.792$ & & & $1.902,0.386$ \\
\hline & Stage II & $11(12.1)$ & $9(9.9)$ & & $7(7.7)$ & $13(14.3)$ & \\
\hline & Stage III & $20(22.0)$ & $18(19.8)$ & & $10(11.0)$ & $28(70.8)$ & \\
\hline & Stage IV & $20(22.0)$ & $13(14.3)$ & & $6(6.6)$ & $27(29.7)$ & \\
\hline \multirow{3}{*}{ Metastasis } & & & & $1.566,0.457$ & & & $7.459,0.024 *$ \\
\hline & Present & $22(24.2)$ & $19(20.9)$ & & $5(5.5)$ & $36(39.6)$ & \\
\hline & Absent & $29(31.9)$ & $20(22.0)$ & & $18(19.8)$ & $31(34.1)$ & \\
\hline \multirow{3}{*}{$\begin{array}{l}\text { History of treatment } \\
\text { modality }\end{array}$} & & & & $1.839,0.175$ & & & $1.113,0.292$ \\
\hline & Chemotherapy & $21(23.1)$ & $11(12.1)$ & & $6(6.6)$ & $26(28.6)$ & \\
\hline & Chemotherapy + surgery & $30(33.0)$ & $29(31.9)$ & & $17(18.7)$ & $42(46.2)$ & \\
\hline \multirow{3}{*}{ Comorbidity } & & & & $\begin{array}{l}5.038 \\
0.025 *\end{array}$ & & & $0.252,0.616$ \\
\hline & Present & $6(6.6)$ & $0(0)$ & & $1(1.1)$ & $5(5.5)$ & \\
\hline & Absent & $45(49.5)$ & $40(44.0)$ & & $22(24.2)$ & $63(69.2)$ & \\
\hline
\end{tabular}

** Significant at $p<0.01 ; *$ significant at $p<0.05$.

TABLE 8: Relationship among pain-related parameters and adequacy of management and pain interference at the ACSH oncology unit, Mekelle, Ethiopia, April 2019 ( $n=91)$.

\begin{tabular}{|c|c|c|c|c|c|c|c|}
\hline \multicolumn{3}{|c|}{ Adequacy of treatment, $n(\%)$} & \multirow{2}{*}{$\begin{array}{l}\text { Association } \\
X^{2}, p \text { value }\end{array}$} & \multicolumn{3}{|c|}{$\begin{array}{l}\text { Pain functioning interference } n \\
(\%)\end{array}$} & \multirow{2}{*}{$\begin{array}{l}\text { Association } \\
X^{2}, p \text { value }\end{array}$} \\
\hline 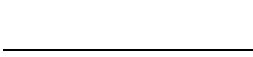 & Adequate & Inadequate & & No/mild & Modera & e/severe & \\
\hline \multirow{3}{*}{ History of pain } & & & & $5.716,0.017$ & & & $\begin{array}{c}19.395 \\
0.000 * * *\end{array}$ \\
\hline & Present & $44(48.4)$ & $26(28.6)$ & & $\begin{array}{c}10 \\
(11.0)\end{array}$ & $\begin{array}{c}60 \\
(65.9)\end{array}$ & \\
\hline & Absent & $7(7.7)$ & $14(15.4)$ & & $\begin{array}{c}13 \\
(14.2) \\
\end{array}$ & $8(8.8)$ & \\
\hline \multirow{4}{*}{ Types of pain } & & & & $\begin{array}{r}11.340 \\
0.010 * *\end{array}$ & & & $\begin{array}{c}31.225 \\
0.000 * * *\end{array}$ \\
\hline & Nociceptive pain & $6(6.6)$ & $10(11.0)$ & & $4(4.4)$ & $\begin{array}{c}12 \\
(13.2)\end{array}$ & \\
\hline & Neuropathic pain & $11(12.1)$ & $2(2.2)$ & & $4(4.4)$ & $9(9.9)$ & \\
\hline & Mixed & $28(30.8)$ & $16(17.6)$ & & $2(2.2)$ & $\begin{array}{c}42 \\
(46.2) \\
\end{array}$ & \\
\hline \multirow{5}{*}{ Pain severity } & & & & $5.508,0.138$ & & & $\begin{array}{c}45.536 \\
0.000 * * *\end{array}$ \\
\hline & No pain & $6(6.6)$ & $0(0)$ & & $6(6.6)$ & $0(0)$ & \\
\hline & Mild & $13(14.3)$ & $14(15.4)$ & & $\begin{array}{c}15 \\
(16.5)\end{array}$ & $\begin{array}{c}12 \\
(13.2)\end{array}$ & \\
\hline & Moderate & $28(30.8)$ & $22(24.2)$ & & $2(2.2)$ & $\begin{array}{c}48 \\
(52.7)\end{array}$ & \\
\hline & Severe & $4(4.4)$ & $4(4.4)$ & & $0(0)$ & $8(8.8)$ & \\
\hline \multirow{5}{*}{$\begin{array}{l}\text { Class of analgesics } \\
\text { administered }\end{array}$} & & & & $\begin{array}{l}53.253 \\
0.000 * *\end{array}$ & & & $\begin{array}{l}17.479 \\
0.001 * *\end{array}$ \\
\hline & No analgesics & $6(6.6)$ & $32(35.2)$ & & $\begin{array}{c}17 \\
(18.7)\end{array}$ & $\begin{array}{c}21 \\
(23.1)\end{array}$ & \\
\hline & No opioids \pm adjuvant & $4(4.4)$ & $6(6.6)$ & & $0(0)$ & $\begin{array}{c}10 \\
(11.0)\end{array}$ & \\
\hline & $\begin{array}{c}\text { Weak } \\
\text { opioids } \pm \text { nonopioids } \pm \text { adjuvant }\end{array}$ & $24(26.4)$ & $2(2.2)$ & & $1(1.1)$ & $\begin{array}{c}25 \\
(27.5)\end{array}$ & \\
\hline & $\begin{array}{c}\text { Strong } \\
\text { opioids } \pm \text { nonopioids } \pm \text { adjuvant }\end{array}$ & $17(18.7)$ & $0(0)$ & & $5(5.5)$ & $\begin{array}{c}12 \\
(13.2)\end{array}$ & \\
\hline
\end{tabular}


TABle 8: Continued.

\begin{tabular}{|c|c|c|c|c|c|c|c|}
\hline & \multicolumn{2}{|c|}{ Adequacy of treatment, $n(\%)$} & \multirow{2}{*}{$\begin{array}{l}\text { Association } \\
X^{2}, p \text { value }\end{array}$} & \multicolumn{3}{|c|}{$\begin{array}{l}\text { Pain functioning interference } n \\
\qquad(\%)\end{array}$} & \multirow{2}{*}{$\begin{array}{l}\text { Association } \\
X^{2}, p \text { value }\end{array}$} \\
\hline & Adequate & Inadequate & & No/mild & Modera & /severe & \\
\hline \multirow{5}{*}{$\begin{array}{l}\text { Pain interference } \\
\text { severity }\end{array}$} & & & & $\begin{array}{r}8.799 . \\
0.032 *\end{array}$ & & & \multirow[t]{5}{*}{$91.0,0.000 * * *$} \\
\hline & No interference & $1(1.1)$ & $0(0)$ & & $1(1.1)$ & $0(0)$ & \\
\hline & Mild & $11(12.1)$ & $11(12.1)$ & & $\begin{array}{c}22 \\
(24.2)\end{array}$ & $0(0)$ & \\
\hline & Moderate & $15(16.5)$ & $21(23.8)$ & & $0(0)$ & $\begin{array}{c}36 \\
(39.6)\end{array}$ & \\
\hline & Severe & $24(26.4)$ & $8(8.8)$ & & $0(0)$ & $\begin{array}{c}32 \\
(35.2)\end{array}$ & \\
\hline
\end{tabular}

$* * *$ Significant at $p<0.001 ; * *$ significant at $p<0.01 ; *$ significant at $p<0.05$.

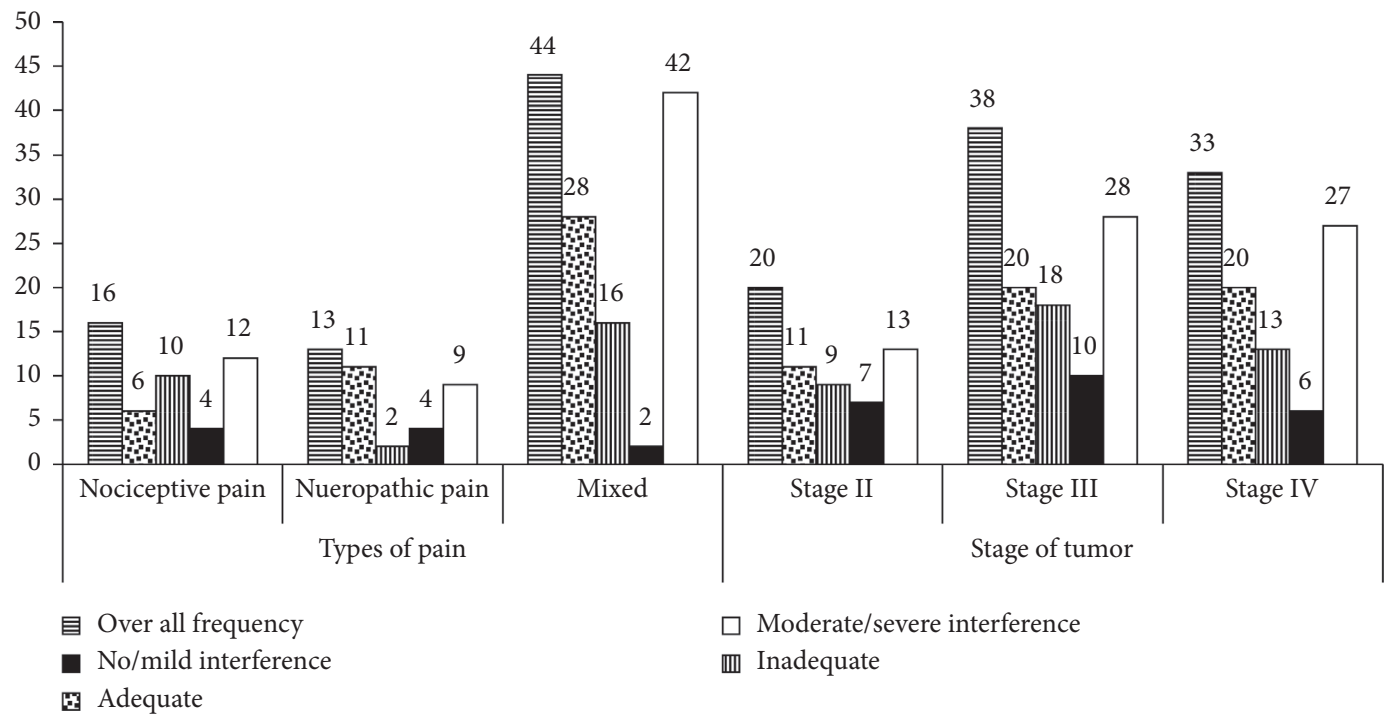

FIGURE 3: Frequency of type of pain and stage of tumor in relation with treatment adequacy and pain interference at the oncology unit of ACSH, Mekelle, Ethiopia $(n=91)$.

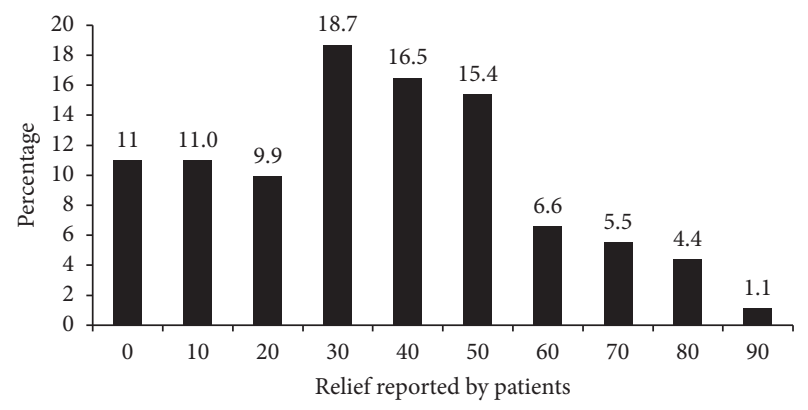

Figure 4: Percentage of relief reported by the patients at the oncology unit of ACSH, Mekelle, Ethiopia.

The study revealed that a significant association of inadequacy of pain management was observed with marital status, level of education, presence of comorbidity, types of pain and pain severity, and activity functioning interference. This finding was similar to the study conducted in the University of Gondar [16].
Cancer-related pain may have interference with daily activities. This study found that almost all (98.9\%) cancer patients experienced cancer pain interference in their daily activities. This figure is higher when compared to the result of a study from Northern Ethiopia in which it was found to be $89.2 \%$ [16].

Interference of CRP with daily activities is highly affected by stage of cancer. This study found that cancer patients with stages II, III, and IV have no/mild and moderate/severe pain interferes with their daily activities (no/mild, moderate/severe pain: $7.7 \%$, $14.3 \% ; 11 \%, 30.8 \%$; and $6.6 \%, 29.4 \%$, respectively). This study's result was comparable with findings of the study from Gondar (no/mild, moderate/severe pain: 7.2\%, 16.9\%; (18.1\%, 26.5\%; and $7.2 \%, 15.7 \%$, respectively). However, the severe interference of pain in stage IV was higher in our study (29.4\%) relative to that of Gondar (15.7\%) [16].

\section{Conclusion}

In conclusion, cancer-related pain management in Ayder Comprehensive Specialized Hospital is inadequate, and 
some of the patient's pain was not managed appropriately as indicated by negative pain index. Assessment of the knowledge and perception of health professionals working in the oncology unit of ACSH and the availability and affordability of antipain medications should be done to find out their role in the inadequacy of CRP management. In addition, the hospital should develop guidelines and drug use policies specifically for CRP management, and in-service training regarding CRP management should be given to health care providers who are working in cancer centers.

\section{Abbreviations}

BPI-SF: Brief Pain Inventory-Short Form

CRP: Cancer-related pain

CT: Computerized tomography

ECG: Electrocardiograph

ECHO: Echocardiography

EPIC: European pain in cancer

NCCN: National Comprehensive Cancer Network

PMI: $\quad$ Pain management index

WHO: World Health Organization.

\section{Data Availability}

The data used to support the findings of this study are available from the corresponding author upon request.

\section{Ethical Approval}

Ethical approval was obtained from the Health Research and Ethics Review Committee of the College of Health Sciences, Mekelle University, Ethiopia.

\section{Conflicts of Interest}

The authors declare that they have no conflicts of interest.

\section{Authors' Contributions}

$\mathrm{KA}$ and KBT developed the proposal; KA collected and entered the data; KBT, KH, LG, and KA analyzed the data and drafted the manuscript; and LG and HGH were involved in developing and reviewing the manuscript.

\section{Acknowledgments}

The authors would like to thank staff members from the oncology unit of College of Health Sciences, Mekelle University, for their indispensable support throughout the study.

\section{References}

[1] P. Reis-Pina, P. G. Lawlor, and A. Barbosa, "Cancer-related pain management and the optimal use of opioids," Acta Médica Portuguesa, vol. 28, no. 3, pp. 376-381, 2015.

[2] World Health Organization, World Health Statistics 2016: Monitoring Health for the SDGs Sustainable Development Goals, World Health Organization, Geneva, Switzerland, 2016.
[3] G. Apolone and O. Corli, "Pattern and quality of care of cancer pain management. Results from the cancer pain outcome research study group," British Journal of Cancer, vol. 100, no. 10, p. 1566, 2009.

[4] World Health Organization, WHO Guidelines for the Pharmacological and Radiotherapeutic Management of Cancer Pain in Adults and Adolescents, World Health Organization, Geneva, Switzerland, 2018.

[5] K. Popat, K. McQueen, and T. W. Feeley, "The global burden of cancer," Best Practice \& Research Clinical Anaesthesiology, vol. 27, no. 4, pp. 399-408, 2013.

[6] A. Caraceni and M. Shkodra, "Cancer pain assessment and classification," Cancers, vol. 11, no. 4, p. 510, 2019.

[7] X. Xu, T. Luckett, A. Y. Wang, M. Lovell, and J. L. Phillips, "Cancer pain management needs and perspectives of patients from Chinese backgrounds: a systematic review of the Chinese and English literature," Palliative and Supportive Care, vol. 16, no. 6, pp. 785-799, 2018.

[8] N. B. Finnerup, S. Haroutounian, P. Kamerman et al., "Neuropathic pain," Pain, vol. 157, no. 8, p. 1599, 2016.

[9] N. Sakakibara, "Negative pain management index scores do not necessarily indicate inadequate pain management: a cross-sectional study," BMC Palliative Care, vol. 17 , no. 1 , p. 102, 2018.

[10] M. T. Greco, A. Roberto, O. Corli et al., "Quality of cancer pain management: an update of a systematic review of undertreatment of patients with cancer," Journal of Clinical Oncology, vol. 32, no. 36, pp. 4149-4154, 2014.

[11] T. Okuyama, "Adequacy of cancer pain management in a Japanese cancer hospital," Japanese Journal of Clinical Oncology, vol. 34, no. 1, pp. 37-42, 2004.

[12] P. Reis-Pina, P. G. Lawlor, and A. Barbosa, "Adequacy of cancer-related pain management and predictors of undertreatment at referral to a pain clinic," Journal of Pain Research, vol. 10, p. 2097, 2017.

[13] F. X. Campion, L. R. Larson, P. J. Kadlubek, C. C. Earle, and M. N. Neuss, "Advancing performance measurement in oncology: quality oncology practice initiative participation and quality outcomes," Journal of Oncology Practice, vol. 7, no. 3, pp. 31-35, 2011.

[14] M. H. Van Den Beuken-Van, "Update on prevalence of pain in patients with cancer: systematic review and meta-analysis," Journal of Pain and Symptom Management, vol. 51, no. 6, pp. 1070-1090, 2016.

[15] F. M. Knaul, "Alleviating the access abyss in palliative care and pain relief-an imperative of universal health coverage: the lancet commission report," The Lancet, vol. 391, no. 10128, pp. 1391-1454, 2018.

[16] H. G. Tegegn and E. A. Gebreyohannes, "Cancer pain management and pain interference with daily functioning among cancer patients in Gondar University Hospital," Pain Research and Management, vol. 2017, pp. 1-12, 2017.

[17] Ayder Comprehensive Specialized Hospital-Meklle University. http://www.mu.edu.et/chs/index.php/ayder-referralhospital.

[18] C. S. Cleeland and K. Ryan, The Brief Pain Inventory, Pain Research Group, 1991.

[19] HIPS, Hunter Integrated Pain Service (HIPS), Brief Pain Inventory, Hunter Integrated Pain Service (HIPS), New Lambton Heights, Australia, 2006, http://www.hnehealth. nsw.gov.au/Pain/Documents/BPI.dec06.pdf.

[20] V. Ventafridda, "Field-testing of the WHO guidelines for cancer pain relief: summary report of demonstration 
projects," Advances in Pain Research and Therapy, vol. 16, pp. 451-464, 1990.

[21] S. Grond, D. Zech, C. Diefenbach, L. Radbruch, and K. A. Lehmann, "Assessment of cancer pain: a prospective evaluation in 2266 cancer patients referred to a pain service," Pain, vol. 64, no. 1, pp. 107-114, 1996.

[22] S. Mercadante, "Pain treatment and outcomes for patients with advanced cancer who receive follow-up care at home," Cancer, vol. 85, no. 8, pp. 1849-1858, 1999.

[23] F. Larue, S. M. Colleau, L. Brasseur, and C. S. Cleeland, "Multicentre study of cancer pain and its treatment in France," British Medical Journal, vol. 310, no. 6986, pp. 1034-1037, 1995.

[24] J. Uki, T. Mendoza, C. S. Cleeland, Y. Nakamura, and F. Takeda, "A brief cancer pain assessment tool in Japanese," Journal of Pain and Symptom Management, vol. 16, no. 6, pp. 364-373, 1998.

[25] A. A. Abruquah, R. P. Biney, E. B. Osei-Bonsu, K. M. Boamah, and E. Woode, "Cancer pain assessment and management in ambulatory patients at a tertiary hospital in Ghana," International Journal of Community Medicine and Public Health, vol. 4, no. 6, pp. 1793-1799, 2017.

[26] P. M. Yates, H. E. Edwards, R. E. Nash et al., "Barriers to effective cancer pain management," Journal of Pain and Symptom Management, vol. 23, no. 5, pp. 393-405, 2002.

[27] S.-N. Lim, H.-S. Han, K.-H. Lee et al., "A satisfaction survey on cancer pain management using a self-reporting pain assessment tool," Journal of Palliative Medicine, vol. 18, no. 3, pp. 225-231, 2015.

[28] S. Yu, X. S. Wang, Y. Cheng, J. Yang, and C. S. Cleeland, "Special aspects of cancer pain management in a Chinese general hospital," European Journal of Pain, vol. 5, pp. 15-20, 2001. 